\title{
Jogos baseados em processos de negócio: Aplicação no treinamento de processos de negócio
}

\author{
Tatiane Neves Lopes ${ }^{1}$, Renata Araujo ${ }^{1,2}$ \\ ${ }^{1} \mathrm{PPgSI}$, Escola de Artes, Ciências e Humanidades - Universidade de São Paulo (USP) \\ São Paulo, SP - Brasil \\ ${ }^{2}$ Faculdade de Computação e Informática - Universidade Presbiteriana Mackenzie (UPM) \\ São Paulo, SP - Brasil \\ \{tatiane.n.lopes, rma.renata.araujo\}@usp.br
}

\begin{abstract}
To adapt to constant changes, organizations that apply business process management need to continuously train their professionals to institutionalize new processes, spending time and effort. This research work presents the proposal of designing, application and effectiveness evaluation of using business-process based digital games in process training. The research methodology to be employed follows the Design Science Research (DSR) approach.
\end{abstract}

Resumo. Para se adaptarem às constantes mudanças, as organizações que realizam gestão de processos de negócio precisam continuamente treinar seus profissionais para institucionalizar novos processos, dispendendo tempo e esforço. Este trabalho apresenta uma proposta para projetar, aplicar e avaliar a efetividade do uso de jogos baseados em processos de negócio ao treinamento de processos organizacionais. A metodologia de pesquisa a ser empregada segue a abordagem Design Science Research (DSR).

\section{Introdução}

No cenário atual, em um ambiente cada vez mais conectado, as tecnologias digitais são o principal gerador de mudanças, não só melhoram a eficiência ou eficácia dos processos de negócio, mas podem levar a uma mudança completa na forma como a organização funciona [Löffler et al. 2019]. As organizações que realizam gestão de processos de negócio $(\mathrm{BPM})$, precisam treinar frequentemente seus profissionais para institucionalizar novos processos e/ou mudanças. Ao considerar as mudanças contínuas no ambiente organizacional, a empresa não pode desprezar o impacto gerado pelas mudanças na força de trabalho da organização e sua abertura para absorver essas mudanças [Perides et al. 2020].

O treinamento de processos é um tema pouco abordado na literatura técnica de gestão de processos, embora seja uma atividade importante e considerada no ciclo de vida da gestão de processos de negócio [Dumas et al. 2018]. O treinamento de processos de negócio pode ser prejudicado para treinar os atores (executores do processo) pela distância entre o processo e seus atores. Desde o momento que o processo é definido até ser efetivamente executado.

É dito que jogos digitais podem servir como ferramenta de complementação de aprendizagem e treinamento ao atuar como alavancas para cativar pessoas para propósitos específicos, desenvolvimento de novos conhecimentos e habilidades, acompanhado de um 
sentimento de tensão e de alegria e de uma consciência de ser diferente da vida cotidiana [Huizinga 2014] [Corti 2006]. Nesta pesquisa, nos interessa o uso de jogos digitais baseados em processos de negócio [Classe 2019], jogos que implementam processos de negócio de forma lúdica e engajante, permitindo aos jogadores entenderem e aprenderem como os processos funcionam, assim como desenvolver consciência sobre seus objetivos. O objetivo da pesquisa é aplicar o Play Your Process (PYP) [Classe et al. 2019], método de design de jogos digitais baseados em processos de negócio, para construir jogos digitais baseados em processos de negócio para o treinamento de processos organizacionais e avaliar a efetividade desses jogos para treinamento. Outro objetivo da pesquisa é adaptar e/ou estender o PYP para a construção de jogos baseados em processos de negócio especificamente para o treinamento de processos.

\section{Apresentação do problema}

As organizações que usam gestão por processos necessitam manter os profissionais atualizados diante das mudanças frequentes que ocorrem nos processos organizacionais [Löffler et al. 2019]. O treinamento de processos é uma etapa importante para a gestão de processos de negócio, onde os processos desenhados para a organização são efetivamente institucionalizados [Dumas et al. 2018].

Entretanto, a institucionalização de processos de negócio pode ser prejudicada pelo tempo e esforço necessário para treinar os atores de um processo desde o momento que o processo é definido ou redesenhado até ser efetivamente executado. Segundo [Thennakoon et al. 2018] poucas pesquisas tem se concentrado nesta área. Como resultado, há uma falta de orientação para as organizações na condução ao treinamento de processos.

Jogos digitais têm sido pensado como alternativa para aprendizagem e treinamento. Eles também são adequados para a área de gestão de processos de negócio para melhor aprender os processos de negócio organizacionais [Classe et al. 2019]. Realizamos um mapeamento sistemático da literatura (MSL), com foco em estudos sobre o uso de jogos digitais para treinamento de processos, foram levantados 22 estudos e observamos que jogos digitais para treinamento de processos é uma área que ainda exige estudos e, mesmo dentre os estudos selecionados, o design e impactos da aplicação de jogos para treinamento de processos se apresenta de forma superficial. Quanto ao impacto do treinamento com o uso dos jogos, os resultados apresentados demonstram que os jogos podem contribuir para o treinamento com uma visão menos cética do processo, colaborando para atingir os objetivos de aprendizagem das tarefas. O trabalho de [Classe et al. 2019] define jogos digitais baseados em processos de negócio e o método Play Your Process para transformar processos de negócios em jogos digitais. A proposta é construir jogos digitais baseados em processos de negócio para explorar seu uso no treinamento de processos organizacionais.

\section{Projeto de pesquisa}

A metodologia de pesquisa utilizada é a Design Science Research (DSR) [Pimentel et al. 2020]. Esta metodologia se baseia na criação ou desenvolvimento de artefatos orientados para a resolução de problemas. A Figura 1 apresenta a estruturação da pesquisa segundo a abordagem epistemológica DSR. 


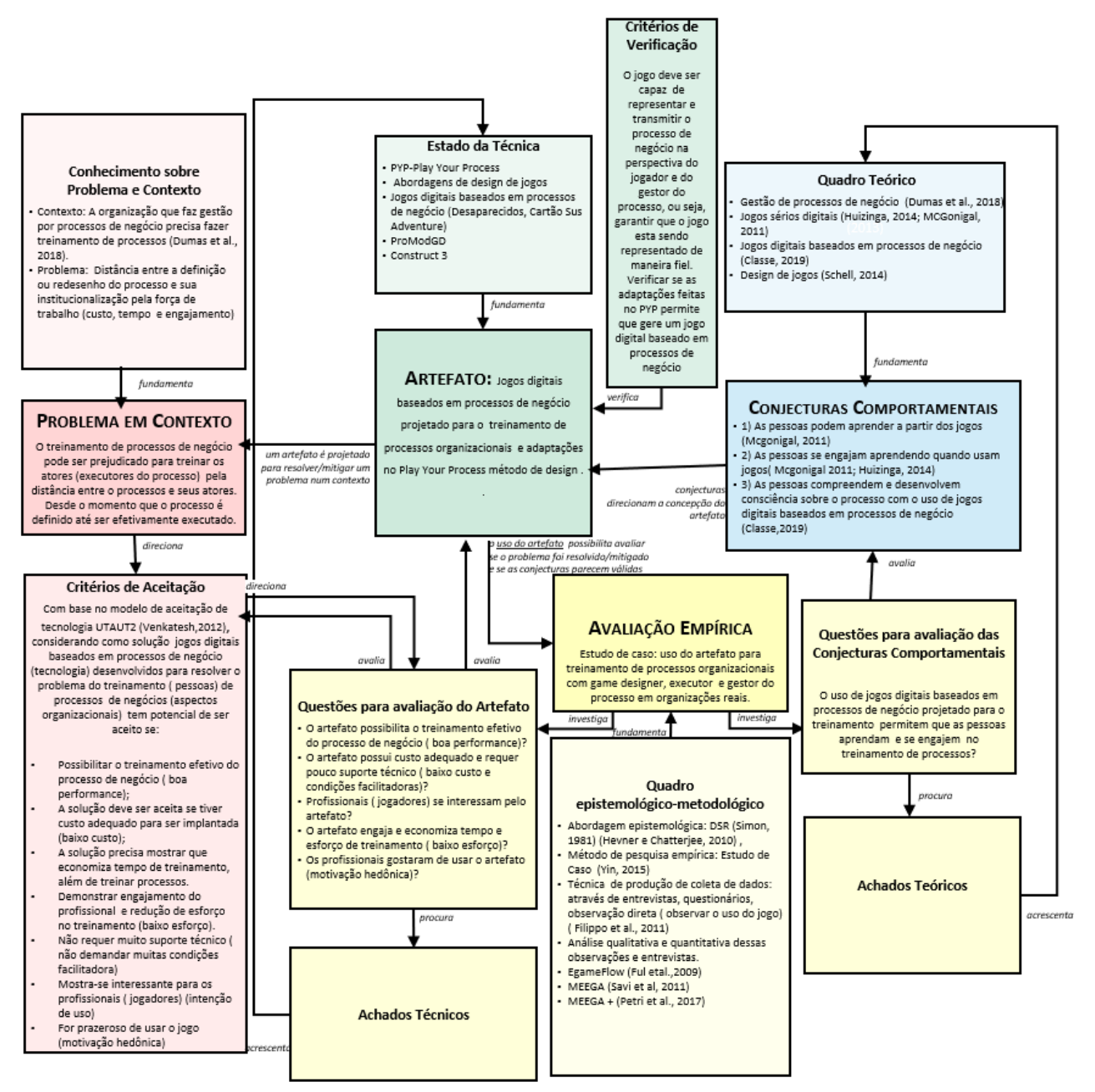

Figura 1. Design da pesquisa baseada em Design Science Research (DSR)

Para a construção dos jogos digitais baseados em processos de negócio, foram previstos dois ciclos. No primeiro, foi realizado um estudo exploratório, onde exploramos a construção de um jogo digital intitulado Mediador Game ${ }^{1}$, para avaliar e coletar impressões e requisitos para o próximo ciclo. A avaliação será realizada com o especialista do processo para observar a percepção atual do jogador, desde o nível de experiência e qualidade, quanto a aprendizagem que o jogo proporciona baseando-se no modelo de avaliação MEEGA+ [Petri et al. 2017]. No segundo ciclo, a pesquisa envolverá prova de conceito em uma multinacional na área de mineração, para colocar em prática e demostrar o design de jogos para treinamento de processos, que será testado com profissionais da empresa.

\section{Projeto de avaliação}

Para a aceitação do artefato, bem como a adequação das conjecturas teóricas, é preciso realizar uma pesquisa empírica fazendo uso do artefato. Optamos por realizar um Estudo de Caso [Yin 2009] para observar se os jogos digitais baseados em processos de negócio permitem que os jogadores aprendam e se engajam. O estudo será realizado com o uso do

\footnotetext{
${ }^{1}$ https://github.com/ciberdem/Mediador-Game
} 
artefato para treinamento de processos organizacionais com game designer, especialistas do processo e o público alvo em organizações reais. A partir dos dados produzidos no estudo empírico, será possível verificar se o artefato se mostrou aceitável para as questões para avaliação das conjecturas comportamentais. (QP1) Como adaptar o Play Your Process para design de jogos digitais baseados em processos de negócio para treinamento?; (QP2) Qual a eficácia de jogos digitais baseados em processos de negócio no treinamento de processos? Considerando as questões para avaliação do artefato (ver Figura 1) a partir dos resultados obtidos por meio de questionários, entrevistas e observações será possível corroborar ou não com a validade das conjecturas téoricas, ao menos dentro do escopo de pesquisa para responder as questões de pesquisa relacionadas tanto a aceitação do artefato quanto adequação das conjecturas teóricas.

\section{Atividades realizadas}

Foi realizado o levantamento bibliográfico, estudo do referencial teórico, estudo do método Play Your Process, realização de um mapeamento sistemático da literatura para identificar trabalhos que usem jogos para treinamento de processos organizacionais. Desenvolvimento do protótipo Mediador Game, escrita de artigos e articulação com empresa para estudo de caso e prova de conceito.

\section{Considerações finais}

Este trabalho tem como objetivo a construção de jogos digitais baseados em processos de negócio projetados para o treinamento de processos organizacionais e adaptações ao método Play Your Process. A proposta está alinhada com Grandes Desafios da área de Sistema de informação no Brasil [Araujo et al. 2017], especialmente "SI e o Mundo Aberto" que tem como subtema "BPM e BPM social".

Com este trabalho, também é esperado que as seguintes contribuições sejam alcançadas: i) para a área de jogos digitais: com a aplicação de jogo digitais baseado em processos de negócio para explorar esse gênero de jogo no contexto do treinamento de processos; ii) para a área de Gestão de Processos de Negócio, espera-se contribuir com uma proposta inovadora para realizar o treinamento de processos com o uso de jogos digitais, capazes de treinar os atores (executores do processo) desde o momento que o processo é definido até ser efetivamente executado. iii) Como contribuições tecnológicas espera-se que este trabalho produza protótipos dos jogos digitais baseados em processos de negócio que contribuam com o treinamento de processos organizacionais e adaptações ao método Play Your Process. Como próximos passos, estudo de caso e prova de conceito (PoC), em parceria com empresa. Desenvolvimento do jogo baseado em processos de negócio para o processo identificado e sessões de treinamento do processo com colaboradores da empresa.

\section{Agradecimentos}

Este trabalho é apoiado em parte pelo Fundo Mackpesquisa e pelo CNPq (313210/2019$5)$.

\section{Referências}

Araujo, R., Maciel, R., and Boscarioli, C. (2017). I grandsi-br: Grandes desafios de pesquisa em sistemas de informação no brasil (2016-2026). Relatório Técnico. Comissão 
Especial de Sistemas de Informação (CE-SI) da Sociedade Brasileira de Computação (SBC). 67p.

Classe, T, M. (2019). Play Your Process - Um Método de Design de Jogos Digitais Baseados em Modelos de Processos de Negócio. PhD thesis, Universidade Federal do Estado do Rio de Janeiro.

Classe, T. M., De Araujo, R. M., Xexéo, G. B., and Siqueira, S. (2019). The play your process method for business process-based digital game design. International Journal of Serious Games, 6(1):27-48.

Corti, K. (2006). Games-based learning; a serious business application. Informe de PixelLearning, 34(6):1-20.

Dumas, M., La Rosa, M., Mendling, J., and Reijers, H. A. (2018). Fundamentals of Business Process Management. Springer, 2nd edition.

Huizinga, J. (2014). Homo ludens ils 86 (vol. 3). Oxon: Routledge.

Löffler, A., Jacoby, D., Faizan, N., Utesch, M., Kienegger, H., and Krcmar, H. (2019). Teaching methods for simulation games: The example of learning business process change. In 2019 IEEE Global Engineering Education Conference (EDUCON), pages 1336-1344. IEEE.

Löffler, A., Jacoby, D., Faizan, N., Utesch, M., Kienegger, H., and Krcmar, H. (2019). Teaching methods for simulation games: The example of learning business process change. In 2019 IEEE Global Engineering Education Conference (EDUCON), pages 1336-1344.

Perides, M. P. N., de Vasconcellos, E. P. G., and Vasconcellos, L. (2020). A gestão de mudanças em projetos de transformação digital: estudo de caso em uma organização financeira. Revista de Gestão e Projetos, 11(1):54-73.

Petri, G., von Wangenheim, C. G., and Borgatto, A. F. (2017). Evolução de um modelo de avaliação de jogos para o ensino de computação. In Anais do XXV Workshop sobre Educação em Computação. SBC.

Pimentel, M., Filippo, D., and Santos, T. M. (2020). Design science research: pesquisa científica atrelada ao design de artefatos. RE@D-Revista de Educação a Distância e Elearning, 3(1):37-61.

Thennakoon, D., Bandara, W., French, E., and Mathiesen, P. (2018). What do we know about business process management training? current status of related research and a way forward. Business Process Management Journal.

Yin, R. K. (2009). Case study research: Design and methods. Thousand Oaks, CA: Sage. The Canadian Journal of Action Research, 14(1):69-71. 